\title{
Aspectos Históricos da Demanda Bioquímica de Oxigênio (DBO) e métodos alternativos com redução no tempo de análise
}

No método tradicional de detecção da Demanda Bioquímica de Oxigênio (DBO) mede-se a diferença na concentração de oxigênio dissolvido (OD) antes e depois de um período de 5 dias de incubação a uma temperatura constante de $20^{\circ} \mathrm{C}$. O método é consideravelmente demorado e não permite tomada de decisões rápidas na remediação de possíveis eventos ambientais em um curto período de tempo. Esta revisão aponta trabalhos das mais diversas áreas de ensino que foram desenvolvidos baseados na premissa da redução do tempo de análise com a proposta de apresentar métodos sustentáveis, baratos e com baixa necessidade de manutenção. Essas novas iniciativas podem contribuir na busca por métodos inovadores e biossustentáveis, como os atuais biossensores. A constante busca por melhorias do método envolvendo a colaboração de vários pesquisadores com áreas de atuação completamente diferentes, com contribuições extremamente importantes para um objetivo comum, demonstram na prática a importância da interdisciplinaridade na pesquisa acadêmica. Para a DBO, a busca por fontes acerca de novos métodos, tecnologias sustentáveis e de fácil aplicabilidade foi elevada. As diversas metodologias disponíveis fornecem alternativas para a redução do tempo de análise e para o monitoramento ambiental em tempo real ou reduzido.

\section{Historical and Methodological Aspects of Biochemical Oxygen Demand (BOD) and alternative methods with reduced analysis time}

\begin{abstract}
In the traditional method of detecting Biochemical Oxygen Demand (BOD), the difference in the concentration of dissolved oxygen (DO) is measured before and after a period of 5 days of incubation at a constant temperature of $20^{\circ} \mathrm{C}$. The method is considerably time-consuming and does not allow making quick decisions on remediation of possible environmental events in a short period of time. This review shows works from various areas of teaching that have been developed based on the premise of reducing the analysis time with the proposal to provide sustainable methods, inexpensive and with low maintenance. These new initiatives can contribute to the search for innovative and biosustainable methods, such as the current biosensors. The constant search for improvements in the method involving the collaboration of several researchers with completely different areas of expertise, with extremely important contributions to a common goal, demonstrate in practice the importance of interdisciplinarity in academic research. For the BOD, the search for sources about new methods, sustainable technologies and easily applied was high. The various methods available provide alternatives to reduce the analysis time and for environmental monitoring in realtime or reduced.
\end{abstract}

Keywords: BOD; Interdisciplinarity; Biosensors; Sustainability; Water Treatment.

Topic: Desenvolvimento, Sustentabilidade e Meio Ambiente

Reviewed anonymously in the process of blind peer.
Received: 06/06/2021

Approved: 28/06/2021
Ana Carla Casagrande Poersch (iD)

Universidade Estadual do Oeste do Paraná, Brasil

http://lattes.cnpq.br/5637561597930918

http://orcid.org/0000-0002-3481-1376

ana.poersch96@gmail.com

Nyamien Yahaut Sebastien

Universidade Estadual do Oeste do Paraná, Brasil

http://lattes.cnpq.br/2977095230414649

http://orcid.org/0000-0002-1144-7903

nyamien@hotmail.com

Jorge Vinicius Takahashi Reimcke (iD

Universidade Estadual do Oeste do Paraná, Brasil

http://lattes.cnpq.br/3011644059001679

http://orcid.org/0000-0003-2288-5498

jorge.vinicius11@hotmail.com
Eleticia Eudalia Camozatto (iD)

Universidade Estadual do Oeste do Paraná, Brasi

http://lattes.cnpq.br/8513764162053322

http://orcid.org/0000-0001-9070-5482

eleticia.camozatto@outlook.com
Referencing this:

POERSCH, A. C. C.; SÉBASTIEN, N. Y.; TAKAHASHI, J. V.; CAMOZATTO, E. E.. Aspectos Históricos da Demanda Bioquímica de Oxigênio (DBO) e métodos alternativos com redução no tempo de análise. Revista Ibero Americana de Ciências Ambientais, v.12, n.6, p.448-460, 2021. DOI: http://doi.org/10.6008/CBPC2179-6858.2021.006.0037 


\section{INTRODUÇÃO}

Existem diversos parâmetros-chave responsáveis por demonstrar de forma prática e objetiva a qualidade de um sistema. A Demanda Bioquímica de Oxigênio (DBO) é uma delas, tratando-se de uma medida indireta da carga orgânica de sistemas aquáticos, considerada como um dos parâmetros principais da legislação vigente brasileira, a Resolução n.357 - CONAMA (2005).

A DBO utiliza as concentrações de oxigênio dissolvido para estimar o material orgânico degradado por microrganismos aeróbicos, como parte de seus processos metabólicos essenciais em um certo período (PND, 2015; EATON, 2017). A análise indica a quantidade de compostos orgânicos biodegradáveis presentes na água, sendo utilizada principalmente para quantificar o grau de contaminação orgânica presente em sistemas hídricos e estações de tratamentos (LORENZO, 2016). Quanto mais elevadas as concentrações de material orgânico, menores os valores de oxigênio disponíveis ao meio, levando à perda de biodiversidade e à degradação de ambientes aquáticos (FERREIRA et al., 2017), prejudicando os usos primordiais da água.

De acordo com Guo et al. (2020), a técnica é demorada, deixando de exibir resultados em tempo real. Muitas empresas e órgãos ambientais frequentemente encontram-se em situações emergenciais que requerem tomadas de decisões operacionais rápidas e eficazes, tornando necessária a quantificação da Demanda Bioquímica de Oxigênio em períodos menores que os cinco dias estipulados pela metodologia tradicional (ISO, 2019).

Em situações práticas, a estimativa da DBO com feedbacks rápidos é extremamente importante para gerenciar estações de tratamento (GUO et al., 2021) e evitar possíveis contaminações ambientais. Durante anos, pesquisadores buscaram encontrar diferentes possibilidades para a realização do método em períodos reduzidos, aumentando a frequência de análises e evitando o uso de compostos insustentáveis ao ambiente. Soluções abrangentes foram encontradas em conceitos interdisciplinares que, de acordo com Moraes (2005), foram introduzidos na pesquisa científica em meados da década de 90. A autora ressalta que a interdisciplinaridade permite tratar de forma conjunta assuntos comuns às diversas áreas de conhecimento, “mediante o estudo de temas comuns, estabelece-se um diálogo entre disciplinas, embora sempre considerando a especificidade de cada área" (MORAES, 2005).

Dessa forma, este artigo revisão comenta à história por trás do desenvolvimento desta antiga metodologia e levanta diversas possibilidades para a realização da análise em períodos de tempo reduzido, introduzindo e comentando métodos que foram trabalhados de forma interdisciplinar.

\section{REVISÃO TEÓRICA}

\section{Aspectos Históricos da Demanda Bioquímica de Oxigênio}

O rio Tâmisa, o mais longo da Inglaterra, percorre um total de $346 \mathrm{~km}$ desde as colinas de Costwold até sua foz, no estuário do Mar do Norte. Ao longo dos séculos o rio fora cercado pela Grande Londres, evoluindo com grandes ocupações espaciais de forma densa e desordenada (OLIVEIRA, 2015).

A combinação de grandes aglomerações, formas de uso do solo e infraestruturas precárias levaram 
a um declínio acentuado da qualidade da água desse rio e seus afluentes, agravando a situação precária da saúde pública (OLIVEIRA, 2015).

Em 1898, a Comissão Real do Reino Unido elaborou uma série de relatórios sobre a situação sanitária do país, contudo, diagnósticos, propostas de ação de longo prazo e a regulação do lançamento de efluentes industriais e domésticos deu-se somente entre 1951 e 1964 (OLIVEIRA et al., 2015; ATTRILL, 1998).

Os relatórios e estudos acarretaram efeitos positivos na qualidade da água, com uma série de altos e baixos ao passar dos anos (OLIVEIRA, 2015), porém a continuidade dos estudos levou ao surgimento de métodos clássicos de pesquisa, como a Demanda Bioquímica de Oxigênio. Em 1909, pesquisadores concluíram que o período de autodepuração de corpos d'água e efluentes completavam-se em um prazo médio de cinco dias, em um ambiente com uma temperatura média de $20 \circ \mathrm{C}$. O valor encontrado a $20 \circ \mathrm{C} \mathrm{e}$ o tempo expresso em dias foi determinado por Phelps (1909), pela reação do azul de metileno para o esgoto de Boston e, posteriormente, pela determinação indireta da demanda bioquímica de oxigênio do esgoto de Washington. Resultados similares também foram computados com os resultados obtidos por Lederer (1914), em Chicago, na comparação dos métodos de diluição e incubação de salitros, usando azul de metileno.

Dessa forma, a DBO foi selecionada como um indicador concreto de poluição orgânica. Ao longo das décadas diversas metodologias foram descritas e replicadas em inúmeros livros e normas, seguindo o padrão proposto pela Comissão Real no início do século XX.

\section{METODOLOGIA}

Atualmente, a DBO é determinada pelo método descrito nas Normas Internacionais ISO 5815-1: 2019. O valor encontrado é expresso em miligramas de oxigênio consumido por litro de amostra durante cinco dias de incubação a $20 \stackrel{\circ}{ }$.

Primordialmente, o processo é governado pelas populações de microrganismos e pela temperatura (SABESP, 1997), sendo a temperatura uma característica física que afeta todos os processos metabólicos dos microrganismos (PRICE et al., 2004). O grande número de substâncias nocivas encontradas no ambiente (de origem natural e antropogênica, orgânicas e inorgânicas), moveram pesquisadores na busca por alternativas mais rápidas e eficazes para avaliar a qualidade dos ambientes naturais e artificiais, como estações de tratamento de efluentes.

A base de dados utilizada para a realização desta revisão foi o Science Direct. Ao todo, cinco palavraschaves nortearam a busca: Biochemical oxygen demand; Assessment methods; Biosensor; Microbial fuel cell biosensors; Water Treatment. Além disso, em posse dos artigos disponibilizados pela plataforma, observouse os estudos citados e correlacionados. Após prévia leitura, foram escolhidos estudos prezassem pelo critério de busca pela redução do tempo de análise.

Os métodos escolhidos para contextualização variam entre dois principais critérios: o oxigênio consumido e a atividade celular de diferentes microrganismos. Além disso, todos os estudos citados se baseiam no princípio de obter resultados rapidamente, melhorando o potencial do monitoramento ambiental ao elevar a frequência de análises (JOUANNEAU et al., 2014). 


\section{RESULTADOS E DISCUSSÃO}

\section{Biossensores}

Os biossensores são dispositivos utilizados para aferir de forma quantitativa ou qualitativa alvos de interesse, empregando elementos de reconhecimento biológico alocados com um sistema de transdução (ANTONACCl et al., 2020). Todo biossensor é composto por três componentes: o elemento biológico imobilizado, responsável por detectar diferentes compostos e gerar um sinal de resposta; o sinal gerado pelo elemento biológico é transformado em uma resposta detectável pelo segundo componente: o transdutor; o terceiro componente é o detector que amplifica e processa os sinais antes de exibi-los (PARKHEY et al., 2019).

Essa técnica é excessivamente atrativa por unir áreas interdisciplinares, para qual os limites nítidos não podem ser facilmente mensurados (COULET, 1991). Com o passar dos anos, inúmeros biossensores foram desenvolvidos para auxiliar na deteç̧ão de metais pesados, tóxicos orgânicos, tóxicos inorgânicos e microrganismos patogênicos (EJEIAN et al., 2018).

A partir da década de setenta foram desenvolvidos detectores extremamente sensíveis às substâncias orgânicas e inorgânicas (KARUBE et al., 1977a; 1977b; HIKUMA et al., 1979; HIKUMA et al., 1988; KULYS et al., 1980; RIEDEL et al., 1988; STRAND et al., 1984; KIM et al., 1999; LEHMANN et al., 1999), cujos sensores estimam a DBO com bactérias imobilizadas em contato direto com o eletrodo de medida.

Diferentes modos de imobilização de microrganismos nos sensores foram utilizados, porém, poucos preconizavam materiais inertes e estáveis no meio ambiente. As mudanças começaram a partir da utilização de hidrogéis biodegradáveis como forma de imobilizar os microrganismos. Hidrogéis de alginato (KUMLANGHAN et al., 2008) e agarose (RAUD et al., 2012; RAUD et al., 2013) são de fácil manuseio, mas insuficientes quanto à estabilidade mecânica (CHAN et al., 1999). O solegel (KWOK et al., 2005; LIU et al., 2009; LIU et al., 2011) é um polímero mais complexo, porém mais resistente mecanicamente, descrito como quimicamente e fotoquimicamente inerte, além de termicamente estável. Segundo os autores, por meio dessas técnicas consegue-se estimar a DBO em até 90 minutos. Estes resultados comparados ao método atualmente utilizado acrescentam um avanço significativo quanto à agilidade do teste. Ao comprovar sua eficiência e demonstrar redução de custos, atrai-se o interesse de implantação de tecnologias semelhantes no mercado.

Suportes sólidos também são considerados como uma opção sustentável para imobilizar microrganismos, a partir da adsorção das células a esses componentes. Fibras de vidro e náilon foram utilizadas por Arlyapov et al. (2012); Rastogi et al. (2003a); Rastogi et al. (2003b). Compostos sólidos podem ser uma alternativa sustentável para a imobilização de microrganismos e a prévia determinação da DBO (em até 22 minutos), ao utilizarem matéria prima proveniente da reciclagem para o desenvolvimento do material. Além disso, os próprios custos de produção podem diminuir significativamente, acrescentando ainda mais vantagens ao processo.

Por fim, o sistema desenvolvido por Liu et al. (2012) é baseado em um biofilme microbiano cultivado na superfície interna de um simples tubo de vidro. O princípio difere, uma vez que os microrganismos não 
entram em contato direto com a sonda de oxigênio. A alíquota circula em fluxo contínuo dentro do tubo de vidro e o consumo de oxigênio é medido na saída do tubo, que contém o biofilme microbiano, reduzindo o tempo de análise para no máximo 8 minutos. Esta nova técnica, além de fornecer uma redução significativa no tempo de análise, trabalha com processos de simples desenvolvimento em laboratório, levando a uma diminuição de custos e aumentando o potencial de implantação no mercado.

Contudo, segundo Jouanneau et al. (2014), em mais de 30\% dos estudos citados, os resultados são irrelevantes para o monitoramento ambiental por não apresentarem dados validados. $\mathrm{O}$ autor continua e comenta que em $60 \%$ dos casos, os biossensores utilizam apenas uma cepa microbiana, contrariando o método de referência (sementes com combinações de cepas microbianas para estimar a DBO de alíquotas com altas concentrações de material orgânico). Além de todos esses pequenos entraves nas pesquisas, a estabilidade operacional é baixa e a faixa de medição não consegue englobar grandes concentrações de material orgânico (MODIN et al., 2012).

Apesar dos primeiros estudos não fornecerem resultados excelentes, a forma interdisciplinar de trabalho e os resultados preliminares podem ser considerados como um grande avanço para a pesquisa acadêmica. Ao unir pesquisadores das mais diversas áreas de ensino, o trabalho torna-se mais diversos e completo. Todos os resultados contribuem de forma significativa para o desenvolvimento de novas tecnologias, de forma ilimitada.

\section{Biossensores Bioluminescentes}

As técnicas rápidas, econômicas, simples e em tempo real para o monitoramento de ambientes impactados são possíveis graças aos métodos de detecção de luminescência, fluorescência, fosforescência e quimioluminescência. A fluorescência tem sido amplamente utilizada ao longo dos anos na realização de análises ambientais em tempo real (WANG et al., 2009).

De acordo com Valeur (2002), a fluorescência ocorre quando radiação eletromagnética incide em uma molécula. Segundo o autor, ao absorver um fóton, determinada molécula é levada a um estado de excitação eletrônica, transitando um elétron de seu estado fundamental para um orbital não ocupado. Essa molécula pode voltar ao seu estado fundamental com a emissão de fluorescência, ou seja, ao emitir fótons.

Os olhos humanos só conseguem detectar a luz visível, em um comprimento de onda entre $700 \mathrm{~nm}$ e $400 \mathrm{~nm}$, porém, formas de radiação como a ultravioleta (abaixo dos $400 \mathrm{~nm}$ ) também são emitidas por diferentes substâncias (ATKINS et al., 2012). Polímeros, superfícies sólidas, soluções surfactantes, membranas biológicas, proteínas, ácidos nucleicos e células vivas são atualmente utilizadas como sondas e parâmetros para a investigação de sistemas físico-químicos, bioquímicos e biológicos (VALEUR, 2002). As técnicas são de alta sensibilidade, ampla faixa de medição, rapidez e facilidade (WANG et al., 2009).

No campo da Limnologia e da Qualidade de Água diversas análises já foram aprimoradas graças às técnicas de fluorescência (WANG, 2009). A sensibilidade, seletividade e robustez requeridas para os bioensaios levaram ao desenvolvimento de consórcios de microrganismos isolados, geneticamente modificados, testados e desenvolvidos especificamente para atender às necessidades de condições adversas 
(GIROTTI et al., 2009).

Partindo desses princípios, a década de noventa originaram estudos com microrganismos bioluminescentes na busca por atalhos para a detecção da DBO. Com a utilização de bactérias marinhas com luminescência natural (Photobacterium phosphoreum) imobilizados em diferentes substratos, Hyun et al. (1993) criaram um biossensor de alta sensibilidade, obtendo resultados em torno de 15 minutos. Segundo Lei et al. (2006), é uma técnica com alta sensibilidade porque permite detectar concentrações muito baixas do analito de interesse, devido aos princípios instrumentais envolvidos: a intensidade da emissão de fluorescência é diretamente proporcional à concentração.

Nos anos dois mil, Sakaguchi et al. $(2003 ; 2007)$ desenvolveram novos sistemas de detecção/medição rápida de DBO utilizando biossensores baseados em recombinantes luminescentes de células de Escherichia coli, com posterior introdução dos genes lux A-E da Vibrio fischeri (sob o controle do promotor tac, plasmídeo p22luxk). De acordo com os autores, a DBO é estimada pela intensidade de emissão da bioluminescência, sendo esta correlacionada com a energia produzida pela utilização de uma fonte de carbono em condições aeróbicas. Por esse método pôde estimar-se a DBO em 2 horas. Além disso, destacaram que se as técnicas aplicadas em seu estudo passassem por processos de micro fabricação, imobilizando e agrupando células em áreas específicas de uma placa para a detecção da DBO, seria possível miniaturizar o sistema e torná-lo portátil. Dessa forma, a aplicação do método poderia ocorrer em tempo real e no campo, aumentando a praticidade do processo (SAKAGUCHI et al., 2003).

A Photobacterium phosphoreum (consórcio naturalmente bioluminescente) foi utilizada para desenvolvimento de um método com os mesmos princípios do anterior, apresentando resultados mais robustos (SAKAGUCHI et al., 2007). O tempo de resposta para a detecção da DBO foi reduzido em mais de $80 \%$, atingindo 25 minutos. 0 sistema não é de alto custo e pode ser facilmente utilizado no campo e em locais de tratamento de águas residuais, além de detectar as mais diferentes concentrações. Segundo os autores, o sistema poderia ser uma poderosa ferramenta para monitorar compostos específicos ao utilizar um gene promotor e genes recombinantes de consórcios luminescentes.

Além dos estudos citados, Kwok et al. (2005) voltaram a trabalhar com o princípio de microrganismos bioluminescentes para estimar a DBO. Os autores criaram um sensor microbiano em miniatura especialmente para estimar as concentrações da DBO em águas residuais. Com uma cultura de microrganismos capazes de assimilar um amplo espectro de poluentes orgânicos, após sua imobilização na ponta de um sensor sensível ao oxigênio, foi possível estimar as concentrações em 20 minutos. As correlações com o método tradicional são altas, acima de 0,9 , demonstrando a efetividade do pequeno "atalho".

No decorrer do tempo, os grandes avanços descritos por Sakaguchi et al. (2007) e Kwok et al. (2005) não foram replicados em campo e em laboratório. Na maioria dos estudos a bioluminescência foi abordada como um método viável para avaliação de microrganismos patogênicos e substâncias tóxicas em corpos d'água, principalmente relacionadas ao controle de efluentes e à eficiência das estações de tratamento (AXELROD et al., 2016; PHILP et al., 2003).

Contudo, para a DBO, uma das análises críticas chave tratando-se do diagnóstico da qualidade de 
água, o processo de implementação de novos métodos tem se mostrado lento e conturbado. Segundo Ejeian et al. (2018) as espécies de Photobacterium phosphoreum e Vibrio fischeri já são utilizadas e comercializados em consórcios para a detecção de componentes tóxicos. Porém, os sensores desenvolvidos especificamente para DBO com as mesmas espécies ainda não foram amplamente disseminados. De acordo com QI et al., (2021), essas espécies apresentam limitações significantes, embora possam ser cultivadas e enriquecidas em grandes quantidades, elas não apresentam a capacidade de utilização de diferentes tipos de matéria orgânica, necessitando de compostos específicos em suas vias metabólicas.

\title{
Células de combustível microbiano
}

As células de combustível microbiano ou microbial fuel cells (MFCs) são baseadas na capacidade de oxidação que uma gama de microrganismos apresenta naturalmente (MODIN et al., 2012).

\begin{abstract}
A célula de combustível microbiana é um dispositivo eletroquímico no qual um substrato é oxidado no compartimento anódico por bactérias que utilizam os elétrons, provenientes da oxidação no seu metabolismo e em seguida o transferem para o ânodo. Os elétrons gerados movem-se através de um condutor externo até o cátodo onde ocorre redução do composto presente no compartimento catódico, geralmente oxigênio, gerando corrente elétrica. (LEHNEN, 2014) (FIGURA 1)
\end{abstract}

De acordo com Jiang et al. (2018) os MFCs utilizam microrganismos como sondas, onde a presença de um composto ou uma mudança nos níveis dos analitos de interesse afeta os processos de transferência de elétrons dos microrganismos, criando uma corrente elétrica. Esse fluxo de elétrons gera uma corrente proporcional à atividade de biodegradação microbiana, permitindo que a Demanda Bioquímica de Oxigênio seja estimada (JOUANNEAU et al., 2014).

Os MFCs foram desenvolvidos especialmente para fornecer energia extra aos microrganismos, porém suas vantagens como biossensores de DBO incluem o tempo de análise mais curto, o intervalo de análise mais amplo e uma manutenção de baixo custo (PARKHEY et al., 2019).

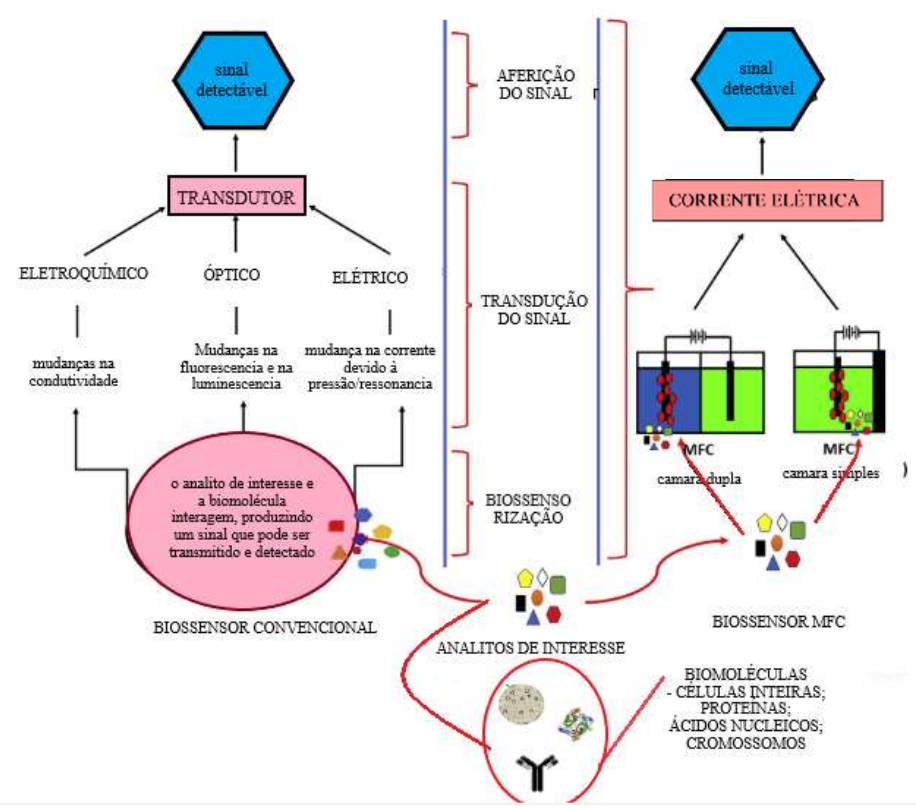

Figura 1: Esquema produzido com base no esquema desenvolvido por Parkhey et al. (2019), detalhando o funcionamento de um biossensor MFC comparado a um biossensor tradicional. 
Esse método foi testado e aplicado por diversos autores no começo dos anos dois mil (GRZEBYK et al., 2005; RABAEY et al., 2005; KIM et al., 2003; CHANG et al., 2004; 2005; JANG et al., 2004; KUMLANGHAN et al., 2007; LORENZO et al., 2009; MOON et al., 2004; PEIXOTO et al., 2011; MIN et al., 2008), porém, poucos foram aplicados em ambientes reais, trabalhando-se somente com padrões de laboratório. Em campo, a variabilidade natural das alíquotas deve ser considerada, e, ao trabalhar somente com padrões conhecidos, a aplicabilidade do futuro sensor é comprometida._Além disso, segundo Lorenzo (2016), para os primeiros MFCs reportados usavam-se mediadores com problemas de consistência e possível toxicidade. Sendo assim, considerados inadequados para aplicações ambientais.

Kim et al. (2003) produziram um MFC sem mediadores e verificaram uma ótima correlação com o método tradicional DBO5 (ISO, 2019) $\left(r^{2}=0,999\right)$. Os testes foram realizados em apenas três amostras de água residual, porém os autores relataram a primeira validação em campo de um sensor MFC, demonstrando sua aplicação prática pela primeira vez. O sensor foi operado por um período de 1 ano com altíssima precisão e boa estabilidade. Apesar de trabalharem com um $n$ amostral pequeno, focaram na aplicação prática e na reprodutibilidade dos resultados, conseguindo progressos animadores.

Segundo Modin et al. (2012), os sensores desenvolvidos permitem estimar a DBO em tempo reduzido, no entanto, não possibilitam estimar-se com precisão cargas orgânicas elevadas. Sendo assim, estes sensores tornam-se deficientes ao serem aplicados nos mais diversos meios, como efluentes e afluentes contaminados. Para solucionar esse problema, seguindo os mesmos princípios aplicados nos procedimentos anteriores, os autores Modin et al. (2012) adicionaram pequenas mudanças aos seus experimentos: uma voltagem externa ao biossensor e um substrato de acetato, aumentando a capacidade e a taxa de oxidação biológica dos microrganismos. Verificaram um tempo de resposta entre 5 e 20 horas, mais longo que para a maioria dos biossensores propostos, tempo considerável se comparado com as demais propostas. Porém, o diferencial do proposto por esses autores é a ampla faixa de medição das concentrações de DBO. Com a adição de maiores concentrações de substrato de acetato, o tempo até a oxidação total aumenta (20h), mas compensa ao permitir aferir altas concentrações de carga orgânica, variando de 32 a $1280 \mathrm{mg} / \mathrm{L}$.

Atualmente, a gama de MFCs propostos para estimar a DBO é extensa (PARKHEY et al., 2019). Os pesquisadores conseguiram validar seus resultados em campo, fornecendo dados mais robustos e confiáveis.

Testes de campo e de laboratório sugerem que esses sensores são promissores para substituir a metodologia tradicional, pois oferecem aferições rápidas e on-line (JIANG et al., 2018), traduzindo as mudanças na concentração de matéria orgânica instantaneamente em sinais elétricos (KIM et al., 2003).

Além disso, colocar os MFCs em condições de hibernação é um método de manutenção simples e conveniente, que não afeta os resultados da DBO e prolonga a durabilidade do sensor (GUO et al., 2021). Como os biossensores de MFCs já requerem menos manutenção, comparado a outros biossensores comuns, isso se traduz em ganho para preservação do meio ambiente. 


\section{Novas tecnologias}

Os primeiros biossensores desenvolvidos datam da década de 70 (KARUBE et al., 1977a; 1977b; HIKUMA et al., 1979). A técnica é popular e amplamente utilizada pela comunidade científica para qualificar ambientes aquáticos naturais e efluentes (EJEIAN et al., 2018), mas sensores exclusivos para análise de DBO são escassos no mercado.

O primeiro biossensor de DBO comercializado foi lançado pela Nisshin Denki (Electric) Co. Ltd. em 1983 (IRANPOUR et al., 1997). Atualmente, no mercado a tecnologia de MFCs foi apresentado pela Korbi Co., Ltd. (JOUANNEAU et al., 2014). Recentemente, um biossensor baseado em MFCs sem mediadores foi desenvolvido para monitorar material orgânico biodegradável em águas residuais, apresentando grande potencial para futuramente ser usado como um biossensor comercial para aferir a DBO (ANAM et al., 2017).

Existem vários biossensores no mercado baseados em técnicas fluorescentes (EJEIAN et al., 2018) e, apesar dos biossensores bioluminescentes citados especificamente para a DBO (SAKAGUCHI et al., 2003; SAKAGUCHI et al., 2007; KWOK et al., 2005) apresentarem um tempo de resposta excelente, desvantagens ainda são constatadas. As espécies disponíveis apresentam limitações metabólicas significantes, não formam biofilmes e não são capazes de fornecer um monitoramento online, em tempo real (Ql et al., 2021).

Para suprir essas desvantagens, os pesquisadores entregaram uma nova tecnologia baseada em MFCs (células de combustível microbiano) (GUO et al., 2020; Ql et al., 2021; GAO et al., 2020). Em um biossensor, bactérias eletroativas (EAB) fixadas no compartimento do ânodo são capazes de oxidar matéria orgânica, liberando elétrons, transferindo-os para o ânodo e, posteriormente, para o cátodo através do circuito MFC (GUO et al., 2020). A transferência de elétrons no circuito pode produzir sinais elétricos que serão coletados com registradores de dados e convertidos em concentração de matéria orgânica (GUO et al., 2020; Ql et al., 2021).

De acordo com Ql et al. (2021), esses biossensores usam células inteiras como parte do sensor. Apesar da tecnologia ser baseada em princípios semelhantes aos MFCs, os EABs são biossensores de alerta precoce para a qualidade de sistemas hídricos. Como são sensíveis, os biofilmes podem servir como biocátodos e bioânodos (Ql et al., 2021). Além disso, quando o material orgânico entra em contato com o biofilme, o ânodo pode parar de produzir elétrons, interrompendo a corrente elétrica e fornecendo um alerta instantâneo da presença de possíveis poluentes no ambiente. Segundo esses mesmos autores, os EABs oferecem pouca seletividade, por reagirem com qualquer composto, mas permitem detectar de forma eficiente a presença de poluição.

A determinação da DBO5 (ISO, 2019) ao longo dos 5 dias de incubação pode indicar de forma parcial as concentrações de matéria orgânica, causando possíveis desvios dos valores reais (GUO et al., 2021). Porém, ao conhecer a natureza dos microrganismos envolvidos no processo e utilizá-los como um meio para obter maior precisão, os pesquisadores tornam a análise mais simples e a padronizam, permitindo a comparação dos resultados de diferentes ambientes de forma eficaz.

Segundo Jouanneau et al. (2019) a estimativa rápida da DBO é essencialmente importante para a 
gestão da estação de tratamento de águas e de efluentes (ETAs, ETEs), uma vez que o tempo de retenção da água em estações de tratamento é de cerca de 3 dias.

Todos esses biossensores podem dispensar o uso de técnicos ou especialistas, dispensando ainda o uso de reagentes analíticos. Muitas empresas e laboratórios não fazem o controle de descartes correto, dessa forma, evitar o uso de reagentes agrega muito ao processo e ao meio ambiente. Segundo Silva (2011), os biossensores podem ser confeccionados para uso contínuo, em linha no processo, sem descarte.

\section{CONCLUSÕES}

Os grandes entraves encontrados na metodologia tradicional (ISO, 2019) envolvem procedimentos complicados, que requerem experiência e habilidade substancial em trabalhos técnicos, além de um longo período de espera dos resultados (KWOK et al., 2005), o que dificulta a tomada de decisão, prejudicando os futuros usos das águas.

A implantação de todas as tecnologias citadas, incluindo as que não fornecem monitoramento online em tempo real (SAKAGUCHI et al., 2003; SAKAGUCHI et al., 2007; KWOK et al., 2005), já são grandes conquistas, uma vez que de forma indireta contribuem para a manutenção de um ambiente saudável. Ao conseguir resultados em tempo recorde, mitigando possíveis problemas gerados pelas diferentes formas de poluição, beneficia-se toda uma extensa cadeia dependente dos recursos hídricos.

A busca por métodos inovadores e biossustentáveis, como os atuais biossensores, envolveu a colaboração de vários pesquisadores, de diferentes áreas de atuação, demonstrando na prática a importância e a necessidade da transdisciplinaridade e da interdisciplinaridade na pesquisa acadêmica.

O trabalho em conjunto e sem limitações de ideias proporciona resultados extremamente satisfatórios, aprimorando a gama de conhecimentos e conteúdos adquiridos, contribuindo diretamente com inovações tecnológicas na busca por um ambiente equilibrado e sustentável.

Para a Demanda Bioquímica de Oxigênio, a busca por links entre novos métodos, tecnologias sustentáveis e de fácil aplicabilidade foi consideravelmente numerosa. As diversas metodologias disponíveis fornecem alternativas para a redução do tempo de análise da DBO e para o monitoramento ambiental em tempo real ou em tempo reduzido.

Ao modificar uma metodologia tão cheia de entraves, principalmente relacionados ao tempo, pesquisadores colaboram com o funcionamento do sistema, proporcionando um tratamento eficaz e de qualidade em um corpo hídrico ou em uma estação de tratamento, contribuindo para a manutenção de um ambiente saudável.

A forma transdisciplinar de trabalho, apesar de disfarçada em grande parte dos estudos, contribui de forma notável na formação de mão de obra especializada. O sujeito torna-se transdisciplinar ao conseguir trabalhar em equipe, identificando seu papel em um todo e contribuindo com o aprimoramento da ciência, sem fronteiras.

Ao diminuir os efeitos negativos causados à biodiversidade, contribuir para o uso otimizado de investimentos necessários para tratar um ambiente impactado e fornecer diversos benefícios indiretos para 
instituições, organizações, empresas, estações de tratamento e consumidores finais, a junção de saberes necessárias para estabelecer uma nova metodologia no mercado vence e cumpre o seu papel.

\section{REFERÊNCIAS}

ANTONACCI, A.; SCOGNAMIGLIO, V.. Biotechnological Advances in the Design of Algae-Based Biosensors. Trends in Biotechnology, v.38, n.3, 2020. DOI:

http://doi.org/10.1016/j.tibtech.2019.10.005

ANAM, M.; YOUSAF, S.; SHARAFAT, I.; ZAFAR, Z.; AYAZ, K.; ALI, N.. Comparing natural and artificially designed bacterial consortia as biosensing elements for rapid non-specific detection of organic pollutant through microbial fuel cell. Int J Electrochem Sci, v.12, p.2836-2851, 2017. DOI: http://doi.org/10.20964/2017.04.49

ARLYAPOV, V.; KAMANIN, S.; PONAMOREVA, O.; RESHETILOV, A.. Biosensor analyzer for BOD index express control on the basis of the yeast microorganisms Candida maltosa, Candida blankii, and Debaryomyces hansenii. Enzyme and Microbial Technology, v.50, n.4-5, p.215-220, 2012. DOI: http://doi.org/10.1016/j.enzmictec.2012.01.002

ATTRILL, M. J.. A rehabilitated estuarine ecosystem: The environment and ecology of the Thames estuary. Great Britain: Kluwer Academic Publishers, 1998.

ATKINS, P. W.; JONES, L.. Princípios de química: questionando a vida moderna e o meio ambiente. 5 ed. Porto Alegre: Bookman, 2012.

AXELROD, T.; ELTZOV, E.; MARKS, R. S.. Bioluminescent bioreporter pad biosensor for monitoring water toxicity. Talanta, v.149, p.290-297, 2016. DOI: http://doi.org/10.1016/j.talanta.2015.11.067

BRASIL. Resolução CONAMA n.357, de 17 de março de 2005. Brasília: DOU, 2005.

COULET, P. R.. Biosensor Principles and Applications. New York: Marcel Dekker, 1991.

CHAN, C.; LEHMANN, M.; TAG, K.; LUNG, M.; KUNZE, G.; RIEDEL, K.; GRUENDIG, B.; RENNEBERG, R.. Measurement of biodegradable substances using the salt-tolerant yeast Arxula adeninivorans for a microbial sensor immobilized with poly (carbamoyl) sulfonate (PCS) part I: construction and characterization of the microbial sensor. Biosensors and Bioelectronics, v.14, n.2, p.131-138, 1999.

CHANG, I. S.; JANG, J. K.; GIL, G. C.; KIM, M.; KIM, H. J.; CHO, B. W.; KIM, B. H.. Continuous determination of biochemical oxygen demand using microbial fuel cell type biosensor. Biosensors and Bioelectronics, v.19, n.6, p.607-613, 2004. DOI: http://doi.org/10.1016/S0956-5663(03)00272-0

CHANG, I. S.; MOON, H.; JANG, J. K.; KIM, B. H.. Improvement of a microbial fuel cell performance as a BOD sensor using respiratory inhibitors. Biosensors and Bioelectronics, v.20, n.9, p.1856-1859, 2005. DOI: http://doi.org/10.1016/j.bios.2004.06.003

EATON, A.; FRANSON, M.; ASSOCIATION, A.; ASSOCIATION, A.; FEDERATION, W.. Standard Methods for the
Examination of Water and Wastewater. 23 ed. Washington: American Public Health As- sociation, 2017.

EJEIAN, F.; ETEDALI, P.; MANSOURI-TEHRANI, H, A.; SOOZANIPOUR, A.; LOW, Z. X.; ASADNIA, M.; TAHERIKAFRANI, A.; RAZMJOU, A.. Biosensors for wastewater monitoring: a review. Biosensors and Bioelectronics, v.118, 2018. DOI: $\underline{\text { http://doi.org/10.1016/i.bios.2018.07.019 }}$

FERREIRA, A. R. L.; SANCHES FERNANDES, L. F.; CORTES, R. M. V.; PACHECO, F. A. L.. Assessing anthropogenic impacts on riverine ecosystems using nested partial least square regression. Science of the Total Environment, v.583, p.466477, 2017, DOI: http://doi.org/10.1016/i.scitotenv.2017.01.106

GAO, Y. Y.; YIN, F. J.; MA, W. Q.; WANG, S.; LIU, Y.; LIU, H.. Rapid detection of biodegradable organic matter in polluted water with microbial fuel cell sensor: method of partial coulombic yield. Bioelectrochemistry, v.133, 2020. DOI: http://doi.org/10.1016/i.bioelechem.2020.107488

GIROTTI, S.; FERRI, E. N.; FUMO, M. G.; MAIOLINI, E.. Monitoring of environmental pollutants by bioluminescent bacteria. Analytica Chimica Acta, v.608, n.1, p.2-29, 2009. DOI: http://doi.org/10.1016/j.aca.2007.12.008

GRZEBYK, M., POZNIAK, G.. Microbial fuel cells (MFCs) with interpolymer cation exchange membranes. Separat. Purif. Technol, v.41, n.3, p.321-328, 2005. DOI: http://doi.org/10.1016/j.seppur.2004.04.009

GUO, F.; LIU, H.. Impact of heterotrophic denitrification on $B O D$ detection of the nitrate-containing wastewater using microbial fuel cell-based biosensors. Chem. Eng. J., v.394, 2020. DOI: http://doi.org/10.1016/i.cej.2020.125042

GUO, F.; YUAN, L.; HONG, L.. Hibernations of Electroactive Bacteria Provide Insights into the Flexible and Robust BOD Detection Using Microbial Fuel Cell-Based Biosensors. Science of the Total Environment, v.753, 2021. DOI: http://doi.org/10.1016/j.scitotenv.2020.142244

HIKUMA, M.; SUZUKI, H.; YASUDA, T.; KARUBE, I.; SUZUKI, S.. Amperometric estimation of BOD by using living immobilized yeasts. Eur. J. Appl. Microbiol. Biotechnol, v.8, 289-297, 1979.

HIKUMA, M.; YASUDA, T.. Microbial sensors for estimation of biochemical oxygen demand and determination of glutamate. Methods Enzymol, v.137, p.124-131, 1988.

HYUN, C.-K.; TAMIYA, E.; TAKCUCHI, T.; KARUBE, I.; INOUE, N.. A novel BOD sensor based on bacterial luminescence. Biotechnol. Bioeng, v.41, p.1107-1111, 1993.

ISO. International Organization for Standardization. ISO 5815-1: Water quality - Determination of biochemical oxygen demand after $\mathrm{n}$ days $\left(\mathrm{BOD}_{\mathrm{n}}\right)$. ISO, 2019. 
IRANPOUR, R.; STRAUB, B.; JUGO, T.. Real time BOD monitoring for wastewater process control. Journal of Environmental Engineering, v.123, n.2, p.154-159, 1997.

JANG, J. K.; PHAM, T. H.; CHANG, I. S.; KANG, K. H.; MOON H.; CHO, K. S.; KIM, B. H.. Construction and operation of a novel mediator- and membrane-less microbial fuel cell. Process Biochemistry, v.39, n.8, p.1007-1012, 2004. DOI: http://doi.org/10.1016/S0032-9592(03)00203-6

JIANG, Y.; YANG, X.; LIANG, P.; LIU, P.; HUANG, X.. Microbial Fuel Cell Sensors for Water Quality Early Warning Systems: Fundamentals, Signal Resolution, Optimization and Future Challenges. Renewable and Sustainable Energy Reviews, v.81, p.292-305, 2018. DOI:

http://doi.org/10.1016/j.rser.2017.06.099

JOUANNEAU, S.; GRANGE, E.; DURAND, M.-J.; THOUAND, G.. Rapid BOD assessment with a microbial array coupled to a neural machine learning system. Water Research, v.166, 2019. DOI: http://doi.org/10.1016/j.watres.2019.115079

JOUANNEAU, S.; RECOULES, L.; DURAND, M. J.; BOUKABACHE, A.; PICOT, V.; PRIMAULT, Y.; THOUAND, G.. Methods for assessing biochemical oxygen demand (BOD): $A$ review. Water Research, v.49, n.1, p.62-82, 2014. DOI: http://doi.org/10.1016/j.watres.2013.10.066

KARUBE, I.; MATSUNAGA, T.; MITSUDA, S.; SUZUKI, S.. Microbial electrode BOD sensors. Biotechnology and Bioengineering, v.19, n.10, p.1535-1547, 1977a.

KARUBE, I.; MITSUDA, S.; MATSUNAGA, T.; SUZUKI, S.. A rapid method for estimation of $B O D$ by using immobilized microbial cells. J. Ferment. Technol, v.55, p.243-248, 1997 b.

KIM, B. H.; CHANG, I. S.; GIL, G. C.; PARK, H. S.; KIM, H. J. Novel BOD (biological oxygen demand) sensor using mediator-less microbial fuel cell. Biotechnology Letters, v.25, n.7, p.541-545, 2003.

KIM, M. N.; KWON, H. S.. Biochemical oxygen demand sensor using Serratia marcescens. Biosens. Bioelectron, v.14, p.1-7, 1999.

KULYS, J.; KADZIAUSKIENE, K.. Yeast BOD sensor. Biotechnol. Bioeng, v.22, p.221-226, 1980.

KUMLANGHAN, A.; LIU, J.; THAVARUNGKUL, P.; KANATHARANA, P.; MATTIASSON, B.. Microbial fuel cellbased biosensor for fast analysis of biodegradable organic matter. Biosensors and Bioelectronics, v.22, n.12, p.29392944, 2007. DOI: http://doi.org/10.1016/j.bios.2006.12.014

KWOK, N. Y.; DONG, S.; LO, W.; WONG, K. Y.. An optical biosensor for multi-sample determination of biochemical oxygen demand (BOD). Sensors and Actuators, v.110, n.2, p.289-298, 2005. DOI: http://dx.doi.org/doi:10.1016/j.snb.2005.02.007

LEDERER, A.. The Biochemical Oxygen Demand of Sewages. Journal of Industrial \& Engineering Chemistryv, v.6, n.11, p.882-888, 1914.

LEHMANN, M.; CHAN, C.; LO, A.; LUNG, M.; TAG, K.; KUNZE, G.; RIEDEL, K.; GRUENDIG, B.; RENNEBERG, R.. Measurement of biodegradable substances using the salt-tolerant yeast
Arxula adeninivorans for a microbial sensor immobilized with poly(carbamoly)sulfonate (PCS) Part II: application of the novel biosensor to real samples from coastal and islands regions. Biosens. Bioelectron, v.14, p.295-302, 1999.

LEHNEN, D. R.. Desenvolvimento de Células de Combustível Microbianas. Dissertação (Mestrado em Química) Universidade do Rio Grande do Sul, Porto Alegre, 2014.

LEI, Y.; CHEN, W.; MULCHANDANI, A.. Microbial Biosensors. Analytica Chimica Acta, v.568, n.1-2, p.200-210, 2006. DOI: http://doi.org/10.1016/j.aca.2005.11.065

LIU, C.; MA, C.; YU, D.; JIA, J.; LIU, L.; ZHANG, B.; DONG, S. Immobilized multi-species based biosensor for rapid biochemical oxygen demand measurement. Biosens. Bioelectron, v.26, n.5, p.2074-2079, 2011. DOI: http://doi.org/10.1016/i.bios.2010.09.004

LIU, C.; ZHAO, H.; ZHONG, L.; LIU, C.; JIA, J.; XU, X.; LIU, L.; DONG, S.. A biofilm reactor-based approach for rapid on-line determination of biodegradable organic pollutants. Biosensors and Bioelectronics, v.34, n.1, p.77-82, 2012. DOI: http://doi.org/10.1016/j.bios.2012.01.020

LIU, J.; MATTIASSON, B.. Microbial BOD sensors for wastewater analysis. Water Research, v.36, n.15, p.37863802, 2002.

LIU, L.; SHANG, L.; GUO, S.; LI, D.; LIU, C.; QI, L.; DONG, S.. Organic-inorganic hybrid material for the cells immobilization: long-term viability mechanism and application in BOD sensors. Biosens. Bioelectron, v.25, n.2, p.523-526, 2009. DOl: http://doi.org/10.1016/j.bios.2009.08.004

LORENZO, M.. Use of Microbial fuel cells in sensors. In: Microbial Electrochemical and Fuel Cells: Fundamentals and Applications. London: Woodhead Publishing, 2016.

LORENZO, M.; CURTIS, T. P.; HEAD, I. M.; SCOTT, K.. A singlechamber microbial fuel cell as a biosensor for wastewaters. Water Research, v.43, n.13, p.3145-3154 2009. DOI: http://doi.org/10.1016/j.watres.2009.01.005

MIN, B.; ANGELIDAKI, I.. Innovative microbial fuel cell for electricity production from anaerobic reactors. Journal of Power Sources, v.180, n.1, p.641-647, 2008. DOI: http://doi.org/10.1016/j.jpowsour.2008.01.076

MODIN, O.; WILÉN, B. M.. A novel bioelectrochemical BOD sensor operating with voltage input. Water Research, v.46, n.18, p.6113-6120, 2012. DOI:

http://doi.org/10.1016/j.watres.2012.08.042

MOON, H.; CHANG, I. S.; KANG, K. H.; JANG, J. K.; KIM, B. H.. Improving the dynamic response of a mediator-less microbial fuel cell as a biochemical oxygen demand sensor. Biotechnology Letters, v.26, n.22, p.1717-1721, 2004.

MORAES, S.. Interdisciplinaridade e transversalidade mediante projetos temáticos. Revista Brasileira de Estudos Pedagógicos, v.86, n.213-214, p.38-54, 2005. DOI: http://dx.doi.org/10.24109/2176-6681.rbep.86i213/214.834

OLIVEIRA, A. F.; LEITE, I. C.; VALENTE, J. G.. Global burden of diarrheal disease attributable to the water supply and 
sanitation system in the State of Minas Gerais, Brazil: 2005.

Ciência e Saúde Coletiva, v.20, n.4, p.1027-1036, 2015. DOI: http://doi.org/10.1590/1413-81232015204.00372014

\section{OLIVEIRA, M. A.. Desafios e perspectivas para a} recuperação da qualidade das águas do Rio Tiête na Região Metropolitana de São Paulo. Tese (Doutorado em Ciências), Universidade de São Paulo, São Paulo, 2015.

OSKAMP, S.. Psychological contributions to achieving an ecologically sustainable future for humanity. Journal of Social Issues, v.56, n.3, p.373-90, 2000.

PARKHEY, P.; MOHAN, S, V.. Biosensing Applications of Microbial Fuel Cell: Approach toward Miniaturization. Biomass, Biofuels, Biochemicals: Microbial Electrochemical Technology: Sustainable Platform for Fuels, Chemicals and Remediation. Elsevier B.V., 2018. DOI: http://doi.org/10.1016/B978-0-444-64052-9.00040-6

PEIXOTO, L.; MIN, B.; MARTINS, G.; BRITO, A. G.; KROFF, P.; PARPOT, P.; ANGELIDAKI, I.; NOGUEIRA, R.. In situ microbial fuel cellbased biosensor for organic carbon.

Bioelectrochemistry, v.81, n.2, p.99-103, 2011. DOI: http://doi.org/10.1016/j.bioelechem.2011.02.002

PHELPS, E. B.. The Disinfection of Sewage and Sewage Filter Effluents. Water-Supply Paper, v.229, 1909.

PHILP, J. C.; BALMAND, S.; HAJTO, E.; BAILEY, M. J.; WILES, S.; WHITELEY, ANDY.; LILLEY, A. K.; HAJTO, J.; DUNBAR, S. A.. Whole cell immobilised biosensors for toxicity assessment of a wastewater treatment plant treating phenolics-containing waste. Analytica Chimica Acta, v.487, n.1, p.61-74, 2003.

PND. Environmental Regulatory Document: Method for Performing Biochemical Oxygen Demand (BOD)

Measurements after $\mathrm{n}$ Days of Incubation in Surface Fresh, Underground (Ground), Drinking, Waste, and Treated Waters. Moscow, 2015.

PRICE, P. B.; SOWERS, T.. Temperature dependence of metabolic rates for microbial growth, maintenance, and survival. Proceedings of the National Academy of Sciences, v.101, p.4631-4636, 2004.

QI, X.; WANG, S.; LI, T.; WANG, X.; JIANG, Y.; ZHOU, Y.; ZHOU, X.; HUANG. X.; LIANG, P.. An Electroactive BiofilmBased Biosensor for Water Safety: Pollutants Detection and Early-Warning. Biosensors and Bioelectronics, v.173, 2021. DOI: http://doi.org/10.1016/j.bios.2020.112822

RABAEY, K.; VERSTRAETE, W.. Microbial fuel cells: novel biotechnology for energy generation. Trends Biotechnol, v.23, n.6, p.291-298, 2005. DOI: http://doi.org/10.1016/j.tibtech.2005.04.008

RASTOGI, S.; KUMAR, A.; MEHRA, N.; MAKHIJANI, S.; MANOHARAN, A.; GANGAL, V.; KUMAR, R.. Development and characterization of a novel immobilized microbial membrane for rapid determination of biochemical oxygen demand load in industrial waste-waters. Biosens.

Bioelectron., v.18, n.1, p.23-29, 2003a.

RASTOGI, S.; RATHEE, P.; SAXENA, T. K.; MEHRA, N. K.; KUMAR, R.. BOD analysis of industrial effluents: 5 days to 5 min. Curr. Appl. Phys., v.3, n.2-3, p.191-194, 2003b.

RAUD, M.; KIKAS, T.. Bioelectronic tongue and multivariate analysis: a next step in BOD measurements. Water Research, v.47, n.7, p.2555-2562, 2013. DOI: http://doi.org/10.1016/j.watres.2013.02.026

RAUD, M.; TENNO, T.; JÕGI, E.; KIKAS, T.. Comparative study of semi-specific Aeromonas hydrophila and universal Pseudomonas fluorescens biosensors for BOD measurements in meat industry wastewaters. Enzyme and Microbial Technology, v.50, n.4-5, p.221-226, 2012. DOI: http://doi.org/10.1016/j.enzmictec.2012.01.003

RIEDEL, K.; RENNEBERG, R.; KUHN, M.; SCHELLER, F.. A fast estimation of biochemical oxygen demand using microbial sensors. Appl. Microbiol. Biotechnol, v.28, p.316-318, 1988

SABESP. Companhia de Saneamento Básico do Estado de São Paulo. NTS 003 - DBO: Demanda Bioquímica de Oxigênio: Método de Ensaio. São Paulo: SABESP, 1997.

SAKAGUCHI, T.; KITAGAWA, K.; ANDO, T.; MURAKAMI, Y.; MORITA, Y.; YAMAMURA, A.; YOKOYAMA, K.; TAMIYA, E.. A rapid $B O D$ sensing system using luminescent recombinants of Escherichia coli. Biosensors and Bioelectronics, v.19, n.2, p.115-121, 2003.

SAKAGUCHI, T.; MORIOKA, Y.; YAMASAKI, M.; IWANAGA, J.; BEPPU, K.; MAEDA, H.; MORITA, Y.; TAMIYA, E.. Rapid and onsite BOD sensing system using luminous bacterial cellsimmobilized chip. Biosensors and Bioelectronics, v.22, n.7, p.1345-1350, 2007. DOI:

http://doi.org/10.1016/j.bios.2006.06.008

SILVA, L. M. C.. Desenvolvimento de biossensores eletroquímicos para fenol e ureia com foco na aplicação ambiental. Tese (Doutorado em Tecnologia de Processos Químicos e Bioquímicos) - Universidade Federal do Rio de Janeiro, Rio de Janeiro, 2015.

STRAND, S. E.; CARLSON, D. A.. Rapid BOD measurement for municipal wastewater samples using a biofilm electrode. J. Water Pollut. Control Fed, v.56, p.464-46, 1984.

VALEUR, B.. Molecular Fluorescence: principles and applications. Weinheim: Wiley-VCH, 2002.

WANG, X.; LIN, J-M.; LIU, M-L; CHENG, X-L.. Flow-based luminescence-sensing methods for environmental water analysis. TrAC Trends in Analytical Chemistry, v.28, n.1, p.75-87, 2009. DOI: http://doi.org/10.1016/j.trac.2008.10.005

A CBPC - Companhia Brasileira de Produção Científica (CNPJ: 11.221.422/0001-03) detém os direitos materiais desta publicação. Os direitos referem-se à publicação do trabalho em qualquer parte do mundo, incluindo os direitos às renovações, expansões e disseminações da contribuição, bem como outros direitos subsidiários. Todos os trabalhos publicados eletronicamente poderão posteriormente ser publicados em coletâneas impressas sob coordenação da Sustenere Publishing, da Companhia Brasileira de Produção Científica e seus parceiros autorizados. Os (as) autores (as) preservam os direitos autorais, mas não têm permissão para a publicação da contribuição em outro meio, impresso ou digital, em português ou em tradução. 